\title{
PROGRESSOS DA NEUROCIRURGIA DURANTE A GUERRA
}

No terreno da medicina, a última guerra mundial, ao lado de horrores, trouxe certas vantagens. Observações muito interessantes e importantes modificações técnicas foram feitas não sòmente por médicos militares como por profissionais civis que se incumbiram, oficialmente ou não, de estudar determinados problemas ligados direta ou indiretamente ao melhor aproveitamento do material humano, ao tratamento dos feridos e à reabilitação profissional e social dos incapacitados física e psicològicamente. No particular da neurologia, se não tivemos a descrição de moléstias novas como ocorreu na guerra anterior, grandes foram os progressos no tocante ao diagnóstico e tratamento dos traumatismos crânio-raquidianos e das lesões periféricas.

Começam a apareoer agora as publicações que nos trazem os novos ensinamentos. O recente livro de Haymacker e Woodhall ${ }^{1}$ é um repositório precioso de documentos sôbre as lesðes dos nervos periféricos causados por traumatismos de guerra; é o primeiro de uma série prometida pelos serviços médico-militares norteamericanos, visando a divulgação das lições diagnósticas e terapêuticas fornecidas pela experiência de guerra e, para sua confecção, foi utilizado o arquivo do Army Institute of Pathology, de Washington. Nêle os autores estudam a disposição geral das raízes, plexos e nervos periféricos, a distribuição dos dermatomas e miotomas, a inervação dos ossos e articulaçôes, a semiologia e semiotécnica das lesões do sistema nervoso periférico, a ação produzida pela contração de musculos isolados, a dissociação de atos motores complexos em seus componentes elementares, a patologia das seç̧ões e o mecanismo das regenerações dos nervos periféricos. Outros livros de igual valor e utilidade virão, sem dúvida, como o provam as numerosas publicações avulsas em várias revistas e comunicações às sociedades neurológicas. The Journal of Nervous and Mental Disease dedicou seu número de maio do corrente ano $^{2}$ à publicação de vários trabalhos interesantes. Comentaremos aqui alguns daqueles referentes ao diagnóstico e tratamento dos traumatismos crânioraquidianos e das lesōes do sistema nervoso periférico. Para patentear ainda mais os progressos da neurocirurgia, comentaremos também duas comunicações feitas,

1. Haymacker, W. e Woodhall, B. - Peripheral nerve injuries. Um volume com 217 páginas, ilustrado com 224 figuras, editado por W. B. Saunders $C^{\circ}$, Philadelphia e Londres, 1945.

2. Pilcher, Cobb - Civilian advances and investigations in neurosurgery during the war. Loc. cit.: 434.

McKendree Graig, W. - Injuries to the central nervous system. Loc. cit.: 451.

Naffziger, H. C. - Injuries to the peripheral system. Loc. cit.: 453.

Sachs, E. - Two important post-war problems in neurological surgery. Loc. cit.: 460 . 
a diminuição da mortalidade e para sustentar o organismo doente até tornar possível a avaliação da extensão de injúria e as indicações cirúrgicas mais urgentes e adequadas.

A guerra ensinou que os traumatismos cranianos nos quais haja lesão cerebral devem ser atendidos por cirurgióes com prática de neurocirurgia. O primeiro curativo pode ser feito por cirurgião geral que deve saber o essencial para o tratamento imediato dos traumatismos cranianos, isto é, não fazer de menos $e$ não fazer de mais (L. Davis). Os primeiros curativos consistem, essencialmente, na limpeza do couro cabeludo em tôrno da ferida, na remoção de fragmentos ósseos ou metálicos superficialmente situados, na ligadura de vasos sangrantes, na introdução de sulfanilamida ou sulfadiazina em pó na profundidade da ferida, na proteção da ferida por pensos estéreis, na administração de hemostáticos e de sulfamidas. Feito isto, o doente será removido para hospital adequado e entregue, caso haja lesão cerebral, ao neurocirurgião. Ascroft, experimentado cirurgião, é bem claro nesta questão, dizendo que é mais útil, depois do primeiro curativo, perder 48-72 horas até instalar o doente em hospital bem aparelhado e sob os cuidados do neurocirurgião habilitado, do que tentar intempestivamente uma intervenção sem aparelhagem apropriada e sem pessoal prático. A questão da aparelhagem é básica. Os resultados que o mesmo Ascroft obteve com sua equipe neurocirúrgica móvel no front foram muito menos favoráveis dos que seria lícito esperar de intervenções feitas em hospital bem adequado onde êle e sua equipe estivessem fixos. A mais delicada intervenção cirúrgica no cérebro, nas mãos mais experimentadas, é danificadora e os danos cerebrais são irreparáveis. Processos cirúrgicos sôbre o crânio não devem ser tentados sem uma unidade eletrocirúrgica, aparelhagem de sucção, equipamento de raios $\mathrm{X}$ apropriado, instrumental próprio e adequado, facilidades para a administração dos vários tipos de anestésicos, aparelhagem para controle das funções cardiovasculares e boa equipe de enfermeiras. Operações incompletas são mais perigosas para o paciente que a demora de algurias horas até a entrega do doente a um neurocirurgião dotado de facilidades de equipamento. Só existem três condições para justificar uma intervenção sob condições adversas: 1 - severo estado de choque, curado o qual o doente deve ser removido ràpidamente para hospital apropriado; 2 - hemorragia intracraniana e compressão cerebral; 3 - quando não há oportunidade para pôr o doente sob cuidados de cirurgião habilitado no espaço de 48 a 72 horas.

A urgência na operação de ferimentos crânio-cerebrais depende se a duramáter foi ou não perfurada, do grau da lesão cerebral, do número e do caráter dos fragmentos penetrantes. Deve haver sempre cuidadoso exame das funções do sistema nervoso central com relato do estado de consciência, da presença dos reflexos, da resposta à dor e outros estímulos, das funções motoras e vegetativas.

Anestesia local não pode ser usada em todos os casos e apesar de que o pentotal sódico tenha demonstrado ser muito eficiente, é absolutamente necessário que a boa respiração seja estabelecida antes que a cabeça e a face sejam recobertas pelos panos do campo cirúrgico. Cuidadosa limpeza da ferida e do campo operatório são absolutamente essenciais. Nas fraturas cominutivas com afundamento, todos os fragmentos ósseos devem ser removidos. Entretanto, a remoção do osso deve ser conservativa e a excisão óssea em bloco não deve ser feita. A duramáter nunca deve ser aberta se estiver intacta, a não ser em casos em que haja hematoma subdural. Deve ser feita cuidadosa vistoria entre a dura-máter e a tábua interna do crânio para evitar deixar algum fragmento ósseo inserido, o que é, quase sempre, causa de abscesso. Nos casos em que a dura esteja dilacerada é permitida a pesquisa de corpos estranhos ósseos ou metálicos, que já tenham dilacerado irremediàvelmente a superfície do cérebro, assim como aspirar coágulos sangüíneos e matéria estranha por sucção delicada. A pesquisa e tentativa de retirada de material profundamente localizado jamais deve ser tentada. Boa 
em novembro de 1944, por Byron Stookey ${ }^{3}$ e Loyal Davis, ‘ à Sociedade Neurológica de New York, em sessão conjunta com a secção de Neurologia e Psiquiatria da Academia de Medicina de New York.

No tocante às conseqüências $e$ ao modo de ação dos traumatismos cranianos, o decorrer da guerra demonstrou o acêrto das afirmativas de Denny-Brown e Russell, que encareceram a importância do fator aceleração na produção da concussão cerebral, afirmando que os fenômenos derivantes da concussão se produzem mais fàcilmente quando a cabeça está livre para movimentar-se em resposta a um golpe que quando ela está fixa. Estudos eletrencefalográficos permitiram a Williams, Raeff e Dow relacionar a gravidade e duração inibitória de um traumatismo cerebral com as modificações do potencial elétrico. Walker demonstrou a existência de uma pequena fase da excitação elétrica cerebral imediatamente após o traumatismo, devida à dèscarga violenta e súbita dos impulsos corticais; esta fase da excitação é seguida, logo depois, da supressão total das funções cerebrais. Windle e colaboradores mostraram que todo o traumatismo craniano provoca edema encefálico e alterações degenerativas nas células do córtex e do tronoo cerebral, refutando, assim, a hipótese das alterações moleculares sem dano estrutural como causa da sintomatologia apresentada pelos traumatizados do crânio. Turner demonstrou que, em grande número de casos, mesmo quando o líquor é hemorrágico, a pressão intracraniana é subnormal; êste fato não constitui indício de severidade mas obriga a cuidados especiais na terapêutica - evitar solutos hipertônicos - e na indicação sistemática da extração do líqüido cefalorraquidiano nos traumatismos cranianos.

Os cuidados e tratamento imediatos dos ferimentos crânio-cerebrais recebidos durante as batalhas não diferem, em princípio, daqueles que merecem os traumatismos ocorridos na vida civil. Que a lesão encefálica é mais importante que a do crânio; que a laceração do couro cabeludo deve ser limpa, desbridada e suturada cuidadosamente plano por plano; que os fragmentos de ossos, de metal ou de qualquer outro corpo estranho devem ser removidos desde que possam ser alcançados fàcilmente sem produzir dano para o tecido cerebral; que os fragmentos de projéteis não devem ser retirados quando estejam profundamente situados; tudo isso, utilizado antes mesmo da guerra, é aceito como básico e constitui a melhor conduta.

De maneira geral, o tratamento dos traumatismos fechados ou abertos do crânio forneceu, nesta guerra, melhores resultados que na anterior porque se conhece melhor o efeito da anoxia cerebral produzida pelo trauma e pela respiração inadequada; é essencial providenciar para a facilitação da passagem do ar, pondo o paciente em posição adequada, impedindo a sufocação pela saliva e pelo vômito. $\mathrm{O}$ uso do oxigênio não só diminui a anoxia como contribui para reduzir a pressão intracraniana. A administração de plasma ou sôro, no decurso do tratamento do choque, também combate o edema cerebral. As infeç̧ões diminuíram com o emprêgo da sulfamida e penicilina. Em tôdas as guerras precedentes, os ferimentos do crânio se infectavam, se não tratados cirùrgicamente, ao fim de poucas horas. Atualmente podem passar até dias antes que as possibilidades de infecção se tornem perigosas. O cuidado no primeiro curativo após o traumatismo, com o controle da hemorragia, limpeza da ferida, aplicação local da sulfonamida em pó ou sob a forma de geléia e a administração de penicilina permitem a remoção dos doentes para hospitais adequados em aparelhagem e material. $O$ melhor conhecimento sôbre o choque, sua prevenção e tratamento, auxiliaram grandemente para

3. Stookey, B. - Surgical considerations in peripheral nerve injuries. Arch. Neurol. a. Psychiat.

4. Davis, L. - The management and treatment of craniocerebral injuries. J. Nervous a. Mental Dis. 101: 470-477 (maio) 1945. 
hemostasia, obtida por clips de prata, eletrocoagulação ou espuma da fibrina, é absolutamente essencial. Para o fechamento, os bordos da dura-máter devem ser aparados e depois reunidos por pontos separados.

Importantes também foram as aquisições no domínio da hemostasia dos ferimentos cranianos. Sob a direção de Edwin Cohn, foram estudadas as aplicações de um novo material, fibrin-foam, preparado com fibrinogênio humano; quando sêco tem aspecto poroso e, aplicado aos ferimentos sangrantes, não é irritante, produzindo rápida hemostasia e sendo fàcilmente absorvido. Esta mesma substância, comprimida sob a forma de folhas delgadas, foi utilizada na reparação de soluções de continuidade da dura-máter. Foi geralmente condenada a substituição das falhas da dura-máter por enxertos de aponeuroses autógenas. Defeitos no crânio são reparados com enxertos de osso autógeno, cartilagem de costela ou materiais aloplásticos tais como o vitálio, a lucite e o tântalo. Cuidados de enfermagem devem ser intensivos e inteligentes: mover freqüentemente os comatosos no leito, cuidar da pele, cuidar da alimentação e ingestão de líqüidos, controle da dor e das perturbações esfinctéricas, reabilitação motora e psíquica.

No que respeita à quimioterapia, várias questōes foram esclarecidas graças aos trabalhos de Botterel, Carmichael e Cone, Hurteau, Watt e Alexander, Ingraham e Cobb Pilcher. Este último chegou às seguintes conclusões: 1 - as sulfamidas, sulfadiazina e sulfatiazol têm efeito irritante sôbre o córtex e produzem fibrose na dura-máter e, além disso, fibrose, gliose e outras alterações reacionais no cérebro. No entanto, em doses moderadas, a sulfanilamida e a sulfadiazina podem ser usadas nos ferimentos cerebrais; 2 - o sulfatiazol pode produzir convulsões graves e mesmo fatais quando aplicado diretamente ao cérebro, devendo seu emprêgo ser proscrito; 3 - a meningite estafilocócica é nìtidamente beneficiada pela administração oral da sulfadiazina; nas meningites estafilocócicas, a penicilina foi ineficaz quando administrada por via intravenosa, ao passo que a administração intratecal diminuiu grandemente a mortalidade; a administração intratecal de penicilina produz irritação meníngea com pleocitose no líqüido cefalorraquidiano, porém, mesmo quando intensas, essas irritações são sempre transitórias sem seqüelas permanentes; os agentes quimioterápicos administrados sistêmicamente sòmente beneficiam os abscessos encefálicos quando êstes estão associados à meningite: tais medicamentos não têm acesso às infecções encapsuladas do sistema nervoso. Loyal Davis é de parecer que o sulfatiazol não seja tão irritante como o julgam outros autores, mòrmente quando usado sob a forma de geléia.

Quanto às conseqüências tardias dos traumatismos cranianos, a mais freqüente é a epilepsia. Não sabemos qual é sua incidência e como reconhecer os casos em que esta complicação vai surgir e como tratá-la. Convulsões podem surgir precocemente, após alguns meses de latência e mesmo após alguns anos: Sachs refere-se a casos em que o síndromo convulsivo ocorreu 20 anos após o traumatismo. Na primeira guerra mundial, os inglêses designaram uma comissão para êste estudo e de seus relatórios chegaram à conclusão que ao firm do primeiro ano, os traumatismos cranianos produziam epilepsia em $2 \%$ dos casos, proporção que, ao fim de 5 anos, passou para $15 \%$; recentemente Ashcroft publicou dados finais sôbre os mesmos casos e relatou que a epilepsia incidiu em $34 \%$. Neste estudo ficou também assinalado que a epilepsia é duas vezes mais freqüente em doentes nos quais houve perfuração da dura-máter $(48 \%)$ que naqueles em que a durameninge ficou intacta (23\%). As possibilidades da incidência da epilepsia aumentam também com a supuração do ferimento craniano.

Para diminuir a incidência da epilepsia tem sido empregada a reconstituição da tábua óssea craniana com matérias plásticas. Mesmo isso, porém, não elimina a possibilidade do aparecimento remoto da epilepsia, pois que esta é devida à lesão da pia-máter e do cérebro e à sucessiva esclerose cicatricial. E isto que deve ser evitado, excisando todo o tecido cerebral traumatizado e substituindo a dura- 
máter e a aracnóide por película de fibrina. E provável que esta substância seja mais útil que a substituição da dura por aponeuroses como era indicado até recentemente. $O$ debridamento cuidadoso das feridas recentes ou a excisão das cicatrizes antigas diminuem muito a incidência desta complicação (German, Watts, Penfield e Erickson, Sachs, Pilcher). O problema da epilepsia pós-traumática é tanto mais grave quanto muitos doentes em que esta complicação se estabeleceu, mesmo depois de operados, não deixam de ser epilépticos. E possível que, nestes casos, a intervenção tenha sido feita já tardiamente. E. Sachs sugere que talvez o emprêgo mais amplo e sistemático da eletrencefalografia em traumatizados do crânio permita despistar a moléstia em fase inicial, isto é, mais acessível aos benefícios da terapêutica cirúrgica. Estes pacientes deverão ser operados antes de ter a primeira convulsão. Sachs aconselha: debridamento apropriado na ocasião do acidente, emprêgo de fibrina para substituir a dura e reconhecer os casos precocemente pela eletrencefalografia.

Foi bastante estudada, também, a questão das seqüelas tardias dos traumatismos cranianos fechados - o síndromo pós-traumático - que se carateriza por cefaléia, mal-estar, nervosidade e por uma variedade de outros sintomas vagos, tais como zumbidos nos ouvidos, parestesias, náuseas, astenia, distúrbios visuais e estado vertiginoso. Muitos classificam êste síndromo como uma neurose póstraumática, mas a tendência moderna é orientada no sentido de encontrar um fundamento orgânico. O problema foi observado sob os pontos de vista neurológico, psiquiátrico e psicológico. Puttnam e colaboradores, e Halsted estudaram as aplicações de importantes baterias de testes psicológicos. Denny-Brown observou doentes durante muitos meses após o traumatismo e se convenceu da origem orgânica de seus distúrbios. De modo geral, concordam vários pesquisadores em que a questão da origem psicogênica ou orgânica pode ser determinada, em um dado caso, pela cuidadosa observação neuro-psicológica.

No que respeita aos traumatismos raquidianos, há geral acôrdo em que a laminectomia descompressiva só tem utilidade em uma das três circunstâncias seguintes : 1 - quando a paralisia e a anestesia foram incompletas ou quando se estabeleceram aos poucos sugerindo a existência de hematoma compressor; 2 - se as radiografias ou as provas manométricas indicarem a existência de bloqueio; 3 - se uma ferida penetrante necessitar de intervenção imediata por causa de contaminação, corpos estranhos ou esquírulas ósseas.

O problema dos nervos periféricos já está parcialmente resolvido, desde que se tenha em conta os conselhos de Huber, Dean Lewis, Frazier, Pollock, Davis e Stookey, ditados após a primeira guerra mundial. Eles reconhecem que, para obter a regeneração nervosa, são necessários os seguintes itens: 1) ambas as extremidades dos nervos devem ser expostas; 2) o neuroma da extremidade central deve ser excisado, a navalha, até que os cilindro-eixos nus sejam expostos; 3) a extremidade periférica deve ser excisada até serem expostos os tubos medulares vazios; 4) as extremidades devem ser postas em contacto sem tensão: as bainhas neurolemais devem ser aproximadas por meio de fio de sêda ou de tântalo e, se isto não for possível, elas devem ser dispostas em um leito de plasma coagulado para que os cilindro-eixos tenham uma ponte pela qual possam crescer.

A cirurgia dos nervos periféricos deu também margem a trabalhos importantes. Young e Medowar (Inglaterra) descreveram a união dos cotos de nervos periféricos pelo plasma coagulado. Tarlow, completando êstes estudos, verificou ser mais útil o plasma coagulado do próprio paciente e, para sua obtenção rápida, aperfeiçou a técnica de sua preparação na própria sala de cirurgia e ideou aparelhagem especial para as suturas de plasma coagulado. Para as suturas dos nervos, Burch, Carney e Brown lançaram mão do tântalo, metal plástico e não irritante que pode ser fabricado em delgados e fortes fios. Este metal é, além disso, opaco ao Raio $\mathrm{X}$, permitindo visualizar as suturas e verificar sua boa localização. Ou- 
tro importante uso do tântalo é sob a forma de tubos para envolver as suturas de nervos como luvas protetoras (Weiss), afim de prevenir a fibrose ao nível da sutura, o que dificultaria a regeneração. Mais difícil é o problema quando o afastamento das extremidades seccionadas não permite aproximação para sutura. Enxertos de nervos foram feitos por Tarlow e Weiss. Nos animais, principalmente com enxertos autógenos, o processo deu bons resultados. No homem é difícil obter enxertos com nervos autógenos. $O$ método dos enxertos em feixe, no qual vários nervos de pequeno calibre são reunidos em feixe, e postos para substituir a solução de continuidade de um nervo calibroso, é de valor limitado, mesmo em animais. Weiss desenvolveu a técnica da preparação de enxertos homógenos secos e gelados, com os quais já obteve alguns sucessos em animais. De maneira geral, porém, tais enxertos não têm dado os resultados esperados, levando Dandy a propor o encurtamento dos membros, com ressecção óssea, a fim de permitir a sutura de nervos ponta a ponta.

Foi bastante desenvolvido o campo de eletrodiagnóstico. Hinsey e Richter, entre outros, estudaram o retôrno da função vegetativa nos nervos em regeneração pelos testes da resistência elétrica da pele. Hinsey estudou também os fatores que influenciam a regeneração dos nervos. Pollock estudou a regeneração nervosa pela relação galvano-tetânica, isto é, a relação existente entre a corrente necessária para produzir fibrilação e aquela necessária para a produção de tetanização: é um indice de que a inervação vai retornando e pode indicar a regeneração das fibras nervosas muito antes que haja qualquer indicação clínica. Também Bronk e Erlanyer estudaram vários fenomenos elétricos e Aird pesquizou a histologia dos músculos enervados. A importância prática de todos êstes estudos reside em permitirem uma apreciação exata do estado da regeneração nervosa, de modo a fornecer indicação sôbre o sucesso de uma sutura nervosa em tempo oportuno para ser tentada segunda intervenção.

O. LANGE 